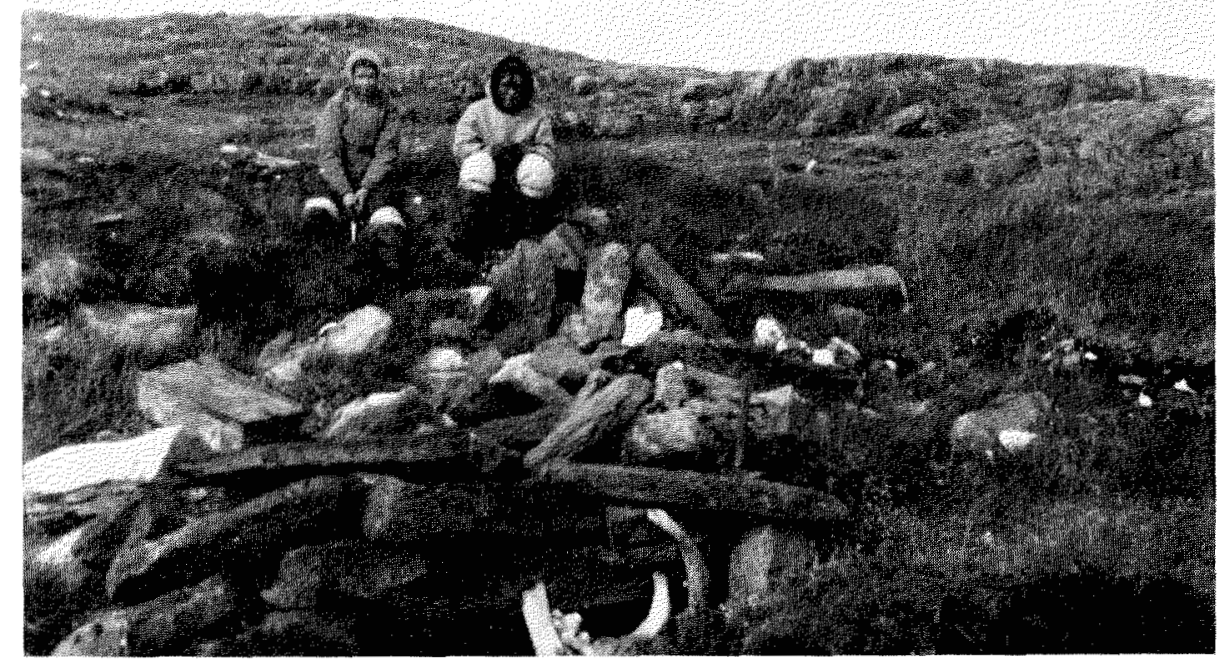

One of the younger Nuwata houses before excavation, August 1938. The porch roof is still intact.

\title{
ESKIMO STONE HOUSES IN FOXE BASIN
}

\section{By T. H. Manning}

$\mathbf{M}$ athiassen (1927a, pp. 113-123, 204-206; map) mentions a number of Eskimo stone house ruins on the Foxe Basin coasts. Some of these sites he visited and described from personal observations; for others he had to rely on Eskimo information and Parry's descriptions (1824). In 1939 Rowley (1940) obtained over 1500 specimens from a Cape Dorset site on Abverdjar Island near Igloolik, but the only signs of dwellings were three or four scarcely visible hollows. In 1949 Rowley excavated some middens on Igloolik Island.

In 1938-40 my wife and I were in the Foxe Basin area, and in 1949 I returned to the same region with an expedition sent out by the Geographical Bureau of the Department of Mines and Resources. Archaeological work was not the main purpose of either expedition but, on the first, houses at three separate sites were excavated and, on the second, three previously unrecorded groups of ruins were found. The specimens from the first expedition, which include both Cape Dorset and Thule types, have not yet been studied in detail, and are stored at the Cambridge University Museum of Archaeology and Ethnology.

In 1938, with Eskimo assistance, we dug at Nuwata and at Storm Cove, both on Foxe Peninsula. At Nuwata, the houses were in three groups about 100 yards apart. The eastern group, which was nearest to - the sea, was about 250 yards inland and 20 feet above high tide level. The western group was at approximately the same height, and the centre 


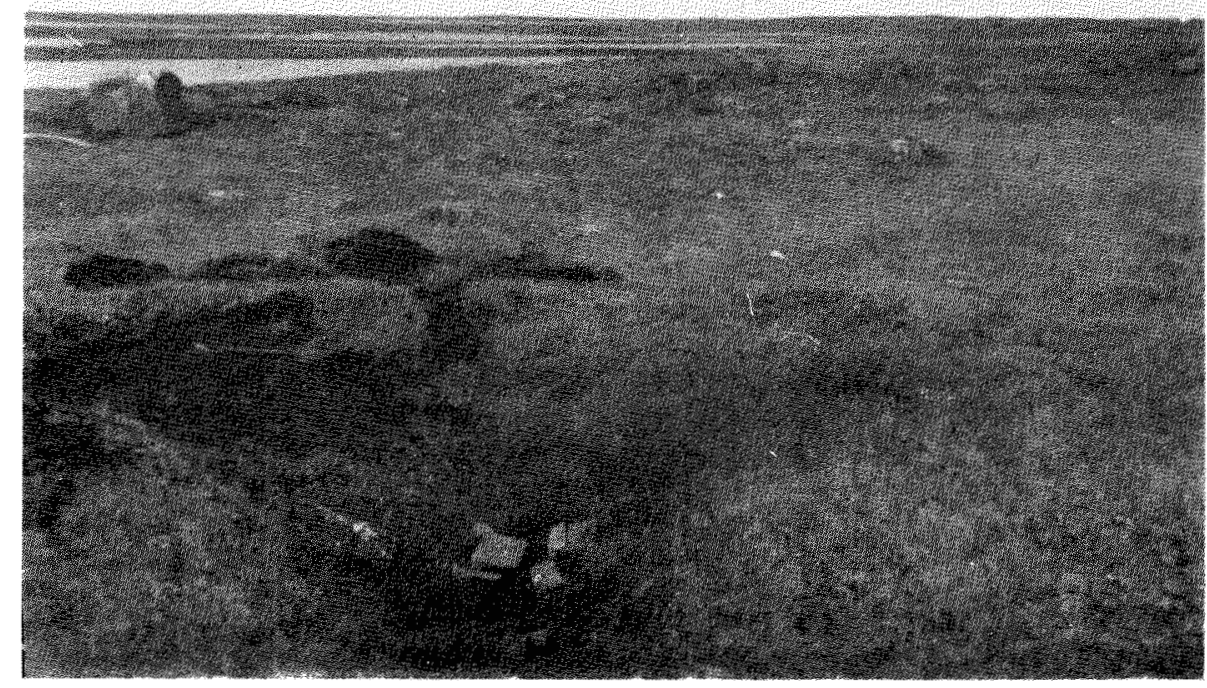

One of the oldest Nuwata houses during excavation, August 1938.

group, of two houses only, was about 15 feet higher. We dug twelve of the twenty-two houses, which apparently varied greatly in age. When we were there the porch roofs were still intact on the youngest houses, which did not appear to be much over one hundred years old. Several of the Nuwata houses, as well as those at Storm Cove, had been disturbed recently by the local Eskimo digging for curios to sell at the trading posts. In addition, they had removed most of the long whalebone roof supports for sledge shoeing and other purposes. The Storm Cove ruins were about a quarter of a mile inland and 50 feet above sea level. There were five houses, all somewhat older than the youngest houses at Nuwata. Of these five, three were excavated.

No Eskimo remains have been found, nor are any to be expected, along the low, flat coastline between Bowman Bay and Taverner Bay. Between the latter place and Piling, as well as up the Hantzsch River, there are numerous small beacons, some of which were probably used in driving caribou, and along the coast there are also tent rings and other old rock structures (Manning, 1943, p. 244). Amongst a group of these just east of Longstaff Bluff, is a possible house ruin.

In 1949 I found a large group of apparently very old strong tent rings and caches between a large lake and the north side of the head of the centre arm of Piling. Nearby there was evidence of a modern snowhouse camp. Less than half a mile away a stone fish trap had been built where a small river flowed out of the lake. This trap is now about 20 feet above tide level; the well built walls, which are about a foot high, can still be seen both below the surface of the stream and on the now dry banks.

We saw no evidence that Eskimo had lived on Prince Charles, Air 


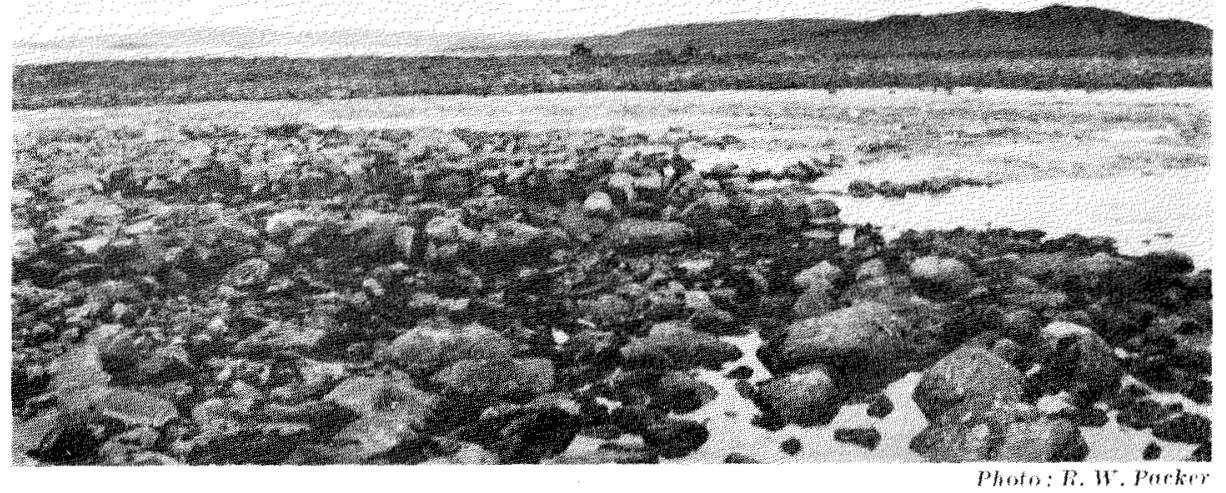

Looking westward from the head of Piling, Longstaff Bluff in distance. Part of the fish trap can be seen in the foreground amongst the boulders and running out under the river.

Force, the Spicer, or Rowley islands, but our visit to the two last was very brief, and we did not land at particularly likely camp sites. On the other two islands we covered a considerable amount of ground, including the comparatively high, dry ground of the northeast points which are the most attractive camping places on the islands. In 1949, however,

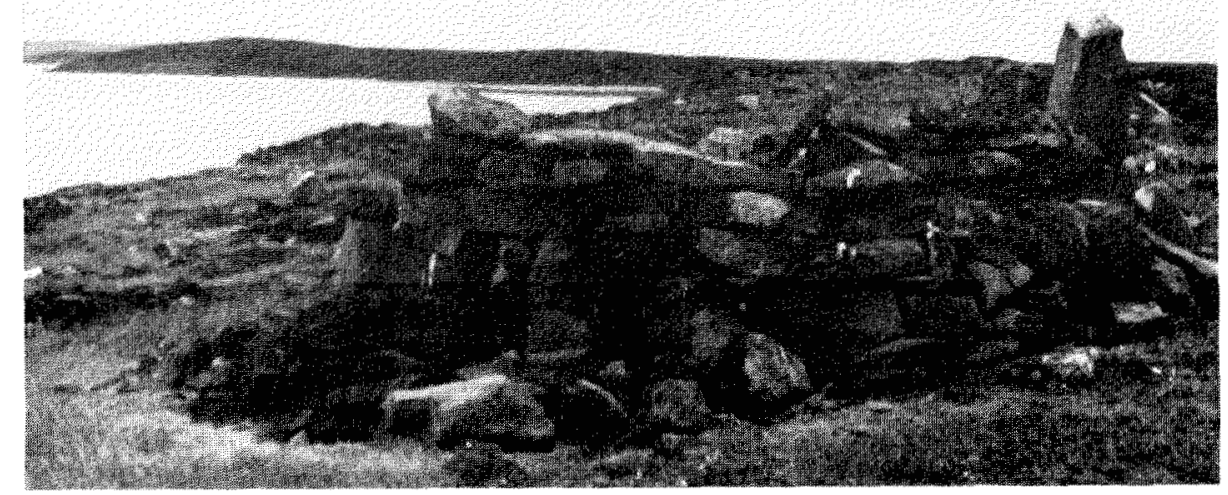

Photo: R. W. Packer

A strong tent ring with unusually high walls at Piling. The cntrance, between two large rocks, was very narrow; at the back there was a distinct bed platform.

when G. W. Rowley was at Igloolik, he was told by an Eskimo that the grandfather of Peewatook (identification disc No. E5-628) had once spent a winter hunting caribou on a large island in eastern Foxe Basin. This island was identified on a large scale map as Prince Charles Island.

Donald Coombs, geographer on the 1949 expedition, found a group of three houses at a height of about 50 feet, near the top of a long, narrow, limestone island (Arnot Island) off Cape Elwyn. They were fairly old, and marked only by a low wall around a shallow depression (oral information). The houses seen on the Calthorpe Islands by Parry (1824, 


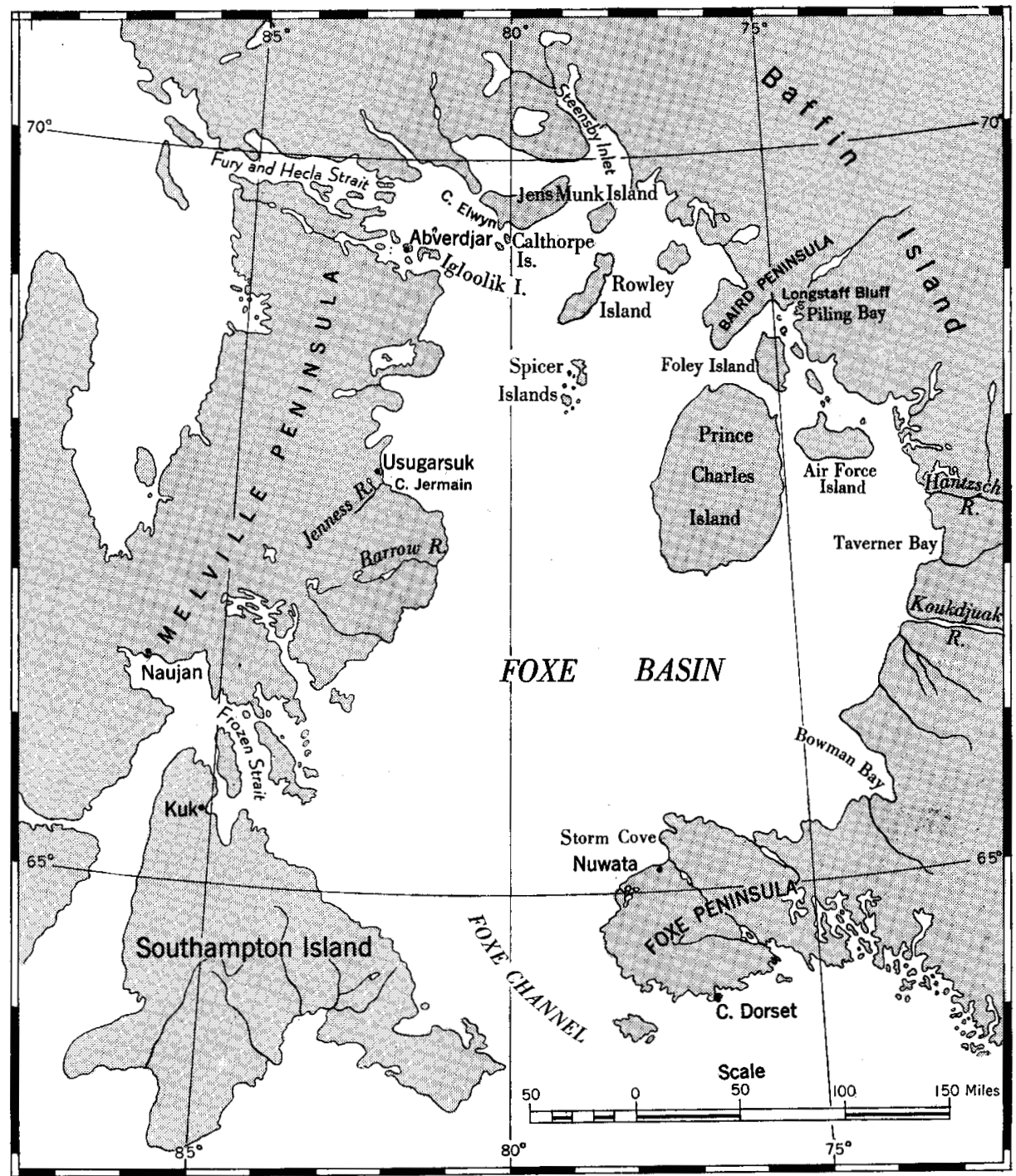

p. 285) were on a gneiss island, and therefore must have been a different group.

In 1940 my wife and I dug part of one of a group of five, or possibly six, houses, nearly half a mile inland and about 100 feet above sea level on the left bank of the Jenness River. These houses must be near those described by Mathiassen (1927a, pp. 115-116) at Usugarsuk. Half-way between the old houses and the sea was the refuse, including numerous tin cans, from a much used snowhouse camp.

In 1949 Coombs discovered a group of houses about half-way across the peninsula on which Cape Jermain is situated. This group consisted of two one-room houses and one two-room house. These houses were very small and of fairly recent date-probably about the age of those on House Island in eastern Hudson Bay (Manning, 1946) or slightly older. than the youngest at Nuwata. There were also four houses on the same level which appeared older, possibly because the rocks and roofing 
materials had been removed for building the younger houses. Beside the houses we found two skulls, an adult and a child, with their respective lower jaws, and a third lower jaw. ${ }^{1}$ The adult skull showed the effects of alveolar abscesses in both upper and lower jaws. A knife or scraper handle, a shoulder blade scraper, and about six walrus bacula which had been fitted and lashed end to end to form a pole were also collected from the surface near the houses. It was from this peninsula, called Anangiarsuk by the Eskimo, that Mathiassen (1927a, pp. 127-129) obtained a small collection of artifacts which originated from a group of Eskimo who starved to death there about 1820 . It is probable that the skulls we found were those of this group and, since the site is too far from the sea for a summer camp-there are no tent rings-and since it is an unlikely place for snowhouses, it can be assumed that these people had been living in the stone houses at the time of their death. Some of the Eskimo on Igloolik Island were living in stone and bone houses in 1823 , and other groups of recently used houses were seen by Parry and Lyon in northwest Foxe Basin. Those actually occupied on Igloolik Island in 1823 were roofed with a temporary cover of skins (Lyon, 1825, p. 280; Parry, 1824, p. 358), but Lyon (pp. 235-236) also describes five houses which, although very dilapidated, were more permanently roofed, and which seemed to have been occupied recently. The Cape Jermain houses also appeared to have had complete roofs, but this is not always easy to determine, nor is it perhaps so important a characteristic as Mathiassen (1927b, pp. 132-134) considered. About half a mile south of the Cape Jermain houses, under a small bluff where good snow could be expected, we found evidence of a comparatively recent winter camp.

Farther down the coast we found several strong tent rings, caches, and other rock structures on the north side of the mouth of the Barrow River. These apparently date from a time when the sea level was 20 or 30 feet higher than at present.

\section{REFERENCES}

Lyon, Capt. G. F. 'Private Journal'. (New edition) 468 pp.; map. London, 1825.

Manning, T. H. "The Foxe Basin coasts of Baffin Island". Geogr. J., Vol. 101 (1943) pp. 225-251; map.

"Ruins of Eskimo stone houses on the east side of Hudson Bay". Amer. Antiquity, Vol. 11 (1946) pp. 201-202.

Mathiassen, Therkel. a) "Archaeology of the Central Eskimos. Pt. I, Descriptive part". Rep. Fifth Thule Exped., 1921-24. Vol. 4, 327 pp.; 85 pp. plates; maps. Copenhagen, 1927.

b) "Archaeology of the Central Eskimos. Pt. II, The Thule Culture and its position within the Eskimo Culture". Rep. Fifth Thule Exped., 1921-24. Vol. 4, 208 pp. Copenhagen, 1927.

Parry, W. E. 'Journal of a second voyage for the discovery of a North-west Passage'. xxx + 571 pp., maps. London, 1924.

Rowley, G. W. "The Dorset Culture of the Eastern Arctic". Amer. Antbrop., Vol. 42 (1940) pp. 490-499.

${ }^{1}$ All now in the National Museum of Canada. 